\title{
Front Matter: Volume 11924
}

, "Front Matter: Volume 11924," Proc. SPIE 11924, Optical Coherence Imaging Techniques and Imaging in Scattering Media IV, 1192401 (9 December 2021); doi: 10.1117/12.2626190

SPIE. Event: European Conferences on Biomedical Optics, 2021, Online Only 


\title{
PROGRESS IN BIOMEDICAL OPTICS AND IMAGING
}

\section{Optical Coherence Imaging Techniques and Imaging in Scattering Media IV}

\author{
Benjamin J. Vakoc \\ Maciej Wojtkowski \\ Yoshiaki Yasuno \\ Editors
}

20-24 June 2021

Online Only, Germany

Sponsored by

The Optical Society (United States)

SPIE

Published by

SPIE 
The papers in this volume were part of the technical conference cited on the cover and title page. Papers were selected and subject to review by the editors and conference program committee. Some conference presentations may not be available for publication. Additional papers and presentation recordings may be available online in the SPIE Digital Library at SPIEDigitalLibrary.org.

The papers reflect the work and thoughts of the authors and are published herein as submitted. The publisher is not responsible for the validity of the information or for any outcomes resulting from reliance thereon.

Please use the following format to cite material from these proceedings:

Author(s), "Title of Paper," in Optical Coherence Imaging Techniques and Imaging in Scattering Media IV, edited by Benjamin J. Vakoc, Maciej Wojtkowski, Yoshiaki Yasuno, Proc. of SPIE-OSA 11924, Seven-digit Article CID Number (DD/MM/YYYY); (DOI URL).

ISSN: 1605-7422

ISSN: 2410-9045 (electronic)

ISBN: 9781510647145

ISBN: 9781510647152 (electronic)

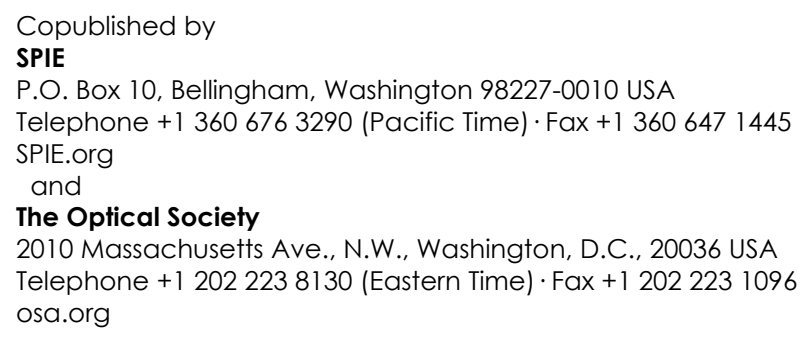

Copyright (C) 2021 Society of Photo-Optical Instrumentation Engineers (SPIE) and The Optical Society

Copying of material in this book for internal or personal use, or for the internal or personal use of specific clients, beyond the fair use provisions granted by the U.S. Copyright Law is authorized by SPIE subject to payment of fees. To obtain permission to use and share articles in this volume, visit Copyright Clearance Center at copyright.com. Other copying for republication, resale, advertising or promotion, or any form of systematic or multiple reproduction of any material in this book is prohibited except with permission in writing from the publisher.

Printed in the United States of America by Curran Associates, Inc., under license from SPIE.

Publication of record for individual papers is online in the SPIE Digital Library.

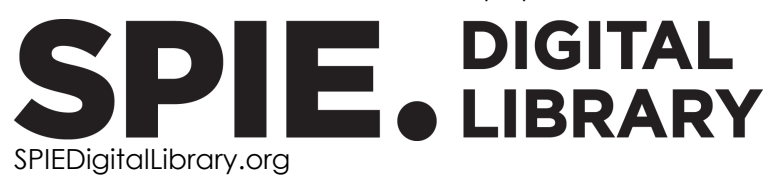

Paper Numbering: A unique citation identifier (CID) number is assigned to each article in the Proceedings of SPIE at the time of publication. Utilization of CIDs allows articles to be fully citable as soon as they are published online, and connects the same identifier to all online and print versions of the publication. SPIE uses a seven-digit CID article numbering system structured as follows:

- The first five digits correspond to the SPIE volume number.

- The last two digits indicate publication order within the volume using a Base 36 numbering system employing both numerals and letters. These two-number sets start with 00, 01, 02, 03, 04, 05, 06, 07, 08, 09, 0A, OB ... 0Z, followed by 10-1Z, 20-2Z, etc. The CID Number appears on each page of the manuscript. 


\section{Contents}

ADVANCES IN EYE IMAGING

1192402 Adaptive glasses wavefront sensorless full-field OCT for high-resolution in-vivo retinal imaging over a wide field-of-view [11924-1]

1192403 Detecting subcellular dynamic behaviours with dynamic full-field OCT on stressed retinal pigment epithelium cell cultures [1 1924-2]

1192404 Spatiotemporal optical coherence (STOC) manipulation for blood flow imaging of the human retina in vivo [1 1924-3]

1192405 Spatial coherence control facilitates high quality in-vivo imaging of retinal and choroidal microstructure with spatio-temporal optical coherence tomography (STOC-T) [1 1924-4]

1192406 Progress on multimodal retinal imaging via OCT and two photon excited fluorescence [11924-5]

1192407 Heartbeat optical coherence elastography to measure corneal stiffness in vivo [11924-6]

\section{ADVANCES IN OPTICAL COHERENCE IMAGING}

1192408 Spatio-temporal optical coherence tomography STOC-T for in-vivo retinal imaging [1 1924-7]

1192409 Video-rate computational adaptive optics optical coherence tomography with a stretchedpulse mode-locked laser [11924-8]

11924 OA Stable and robust stretched-pulse mode-locked wavelength-swept laser for MHz OCT [1 1924-9]

11924 OB Development of an opto-thermo-mechanical theoretical model for photothermal optical coherence tomography imaging of multilayered samples [11924-10]

$119240 \mathrm{C} \quad 80 \mathrm{MHz}$ swept source operating at $1060 \mathrm{~nm}$ based on all-normal-dispersion supercontinuum generation for ultrahigh-speed optical coherence tomography [1 1924-11]

11924 OD An 18.6 MHz wavelength-swept laser source based on stretched-pulse mode-locking at 1290 $\mathrm{nm}$ [11924-12]

11924 OE Axial super-resolution for optical coherence tomography with the iterative adaptive approach [11924-13] 


\section{CLINICAL APPLICATIONS OF OPTICAL COHERENCE IMAGING}

11924 OF Quantifying scattering contrast in intravascular optical coherence tomography for improved atherosclerotic plaque characterization [11924-14]

11924 OG Longitudinal in-vivo quantification of tumour microvasculature heterogeneity via optical coherence tomography (OCT) angiography in a pre-clinical model of radiation therapy [11924-15]

$11924 \mathrm{OH} \quad$ Multi-functional optical coherence microscopy for in-vitro and ex-vivo tissue investigation [11924-16]

$1192401 \quad$ Intracellular Doppler spectroscopy and deep learning in clinical trials to personalize cancer chemotherapy [11924-17]

$119240 \mathrm{~J}$ Objective assessment of corneal transparency in the clinical setting: correction of acquisition artifacts in SD-OCT images and application to normal corneas [11924-18]

11924 OK Brain tumor margin detection using 1.7- $1 \mathrm{~m}$ spectroscopic swept-source OCT [11924-19]

$11924 \mathrm{OL}$ Comparison of two optical coherence tomography systems to identify human brain tumor [11924-20]

\section{NEW TECHNOLOGY FOR MEDICAL INSTRUMENTATION I}

11924 OM Progress in measurements and interpretation of light-evoked retinal function using OCT based optoretinography (ORG) [11924-21]

11924 ON Optoretinography with use of spatio-temporal optical coherence tomography STOC-T [1 1924-22]

1192400 Reconstruction of visible-OCT images based on CGAN using discontinuous RGB superluminescent diode light source [11924-23]

11924 OP Towards densely sampled ultra-large area multi-MHz-OCT for in-vivo skin measurements beyond $1 \mathrm{~cm}^{2} / \mathrm{sec}$ [11924-24]

$119240 Q$ Characterizing the elasticity of skeletal muscle using quantitative micro-elastography [11924-25]

11924 OR Quantification of total haemoglobin concentrations in human whole-blood based on the optical density with spectroscopic optical coherence tomography [11924-26]

11924 OS Image signal-to-noise ratio in optical coherence tomography is dependent upon axial resolution [11924-27] 
POLARIZATION, PHASE AND SIGNAL PROCESSING

11924 OT Endoscopic polarization sensitive optical coherence tomography (PS-OCT) for in-vivo imaging of lungs periphery in bronchial thermoplasty treated asthma patients [11924-28]

11924 OU Polarization-sensitive imaging of diseased and healthy lungs with histological validation [11924-29]

11924 OV Decorrelation-based localized transverse flow measurement by digitally control the lateral resolution in line-field optical coherence tomography [11924-30]

11924 OW Polarization-sensitive OCT using a single-mode fiber-based common-path probe [11924-31]

11924 0X Identification of changes in the microvasculature in mouse brain among different physiological states using optical coherence tomography angiography [11924-32]

\section{SCATTERING AND WAVEFRONT CONTROL}

11924 OY Spectroscopic analysis through thermoelastic optical coherence microscopy [11924-33]

$119240 Z$ Reflection-matrix microscopy for aberration-free imaging through intact mouse skull [1 1924-34]

$1192410 \quad$ Non-invasive Raman signal enhancement in a scattering medium [11924-35]

1192411 Waveguided CARS in air-filled anti-resonant hollow-core fiber [1 1924-36]

$1192412 \quad$ Noise-tolerant wavefront shaping in a Hadamard basis [11924-37]

1192413 Depth invariant feature extraction using deep learning in strong scattering [1 1924-38]

\section{POSTER SESSION}

$1192414 \quad$ Mapping large strains and supra-pixel displacements in phase-sensitive OCT [11924-39]

1192415 System and method for enhancing image quality and resolution in spectral domain OCT [11924-40]

1192416 Fiber-coupled 840-nm broadband SLED-SOA MOPA source integrated in 14-pin butterfly module with $60 \mathrm{~mW}$ output power [11924-41]

1192417 1300-nm ultra-broadband, high-power combined-SLED source integrated in 14-pin butterfly module for UHR-OCT [11924-42]

1192418 Comparison of two approaches for OCT data analysis in white matter imaging [11924-43] 
1192419 Multimodal OCT for in-vivo diagnosis of vulvar lichen sclerosus and evaluate the therapy success [11924-44]

11924 1A Computationally efficient spectral model of OCT-scan formation with easily accounted scatterer motions for simulating multimodal OCT [11924-45]

11924 1B Optical coherence tomography of healthy and malignant tissues: physically reasonable differentiation [1 1924-46]

11924 IC Observation of controlled temperature changes of bone by phase-sensitive optical coherence tomography [11924-47]

11924 ID Full-field optical coherence tomography for optical biopsy applications [1 1924-48]

$11924 \mathrm{IE}$ Identification of demineralization zones in early enamel decay based on image correlation between scanning electron microscope (SEM) and optical coherence tomography (OCT) [11924-49]

$11924 \mathrm{IF} \quad$ Single-shot phase-shifting interferometry using deep learning [11924-50]

11924 IG Corneal ectasia detection from low-resolution images [11924-51]

$11924 \mathrm{1H} \quad$ Improvement of breast cancer histological examination by means of multimodal OCT [11924-52]

$1192411 \quad$ Colorectal neoplastic polyps imaged by fibre-based optical coherence tomography [11924-53]

$119241 \mathrm{~J}$ Chasing sub-micrometer axial resolution in visible optical coherence tomography [11924-54]

$11924 \mathrm{~K} \mathrm{Coherent} \mathrm{averaging} \mathrm{effect} \mathrm{in} \mathrm{speckle} \mathrm{variance} \mathrm{for} \mathrm{optical} \mathrm{coherence} \mathrm{tomography}$ angiography [11924-55]

11924 IL OCT wavenumber calibration with simple reference arm modification [11924-56]

$119241 \mathrm{M} \quad$ Non-destructive identification document inspection with swept-source optical coherence tomography imaging [11924-57]

$11924 \mathrm{iN}$ Time-lapse optical coherence tomography embryo imaging with minimal disturbance [11924-58] 